\title{
Geographical polymorphism of amylase in Drosophila ananassae and its relatives
}

J.-L. Da Lage,

M.-L. Cariou and

J.-R. David
Laboratoire de Biologie et Génétique Evolutives, C.N.R.S, 91198 Gif sur Yvette, France.

Strains of Drosophila ananassae from various places in the Tropics were investigated for their electrophoretical amylase pattern. Eleven isoamylases were found in adult flies. African populations were much more polymorphic than those from the Far East, and showed multibanded phenotypes, suggesting a multiplication of the Amy structural gene, with at least four copies per haploid genome in certain populations. Nine other species of the $D$. ananassae subgroup had weak amylase activity and only one or two variants were found in each species. $D$. monieri and $D$. varians are closely related to $D$. ananassae and showed a single band, similar to the isoamylase 3 of $D$. ananassae, which suggests that this might be an ancestral allele.

\section{INTRODUCTION}

Amylase has been widely studied in Drosophila. Following initial genetic experiments carried out by Abe (1958) and Kikkawa (1960), Kikkawa (1964) and Doane (1964) described several electrophoretic variants of this protein in D. melanogaster. Daïnou et al (1987) reported 12 different isoamylases in this species, which is highly polymorphic in Africa (Hickey, 1979; Daïnou, 1985) and less variable in other parts of the world. $D$. melanogaster was more variable than the other species of the D. melanogaster subgroup (Daïnou et al, 1987). The Amy locus is duplicated in $D$. melanogaster (Bahn, 1967) and throughout the $D$. melanogaster subgroup (Daïnou et al, 1987; Payant et al, 1988). As the amylase duplication has also been found in the $D$. obscura group (Doane and Norman, 1985; Cariou, unpublished data), it is interesting to know whether this extends to other species within the $D$. melanogaster group.

The $D$. ananassae subgroup is included in the D. melanogaster group and is divided into three complexes: ananassae, bipectinata and ercepeae. All the 21 presently known species are tropical. Two of them are circumtropical, $D$. ananassae and D. malerkotliana (David and Tsacas, 1981), and most of the others are endemic to Pacific archipelagos or to South-East Asia where D. ananassae is thought to be native (Dobzhansky and Dreyfus,
1943; McEvey et al, 1987). A few species have been found in the Afrotropical region: D. lachaisei, $D$. parabipectinata, D. ercepeae, D. vallismaia (Tsacas, 1984; Lemeunier et al, 1986). D. ananassae is a domestic species, sometimes abundant in human habitats. It exhibits some unusual genetic features, such as spontaneous male crossing over, segregation distortions, very high inversion frequency, translocations and high mutability (Singh, 1985).

Here we analyse the amylase electrophoretic patterns in numerous strains collected around the Tropical belt.

\section{MATERIALS AND METHODS}

The characteristics of the populations or strains of $D$. ananassae studied are given in table 1. Some of them have been recently collected while others have been kept in the laboratory since the early sixties.

The related species studied are the following: D. malerkotliana (one mass culture from Ivory Coast, three isofemale lines from Madagascar and eight isofemale lines from Ecuador); D. bipectinata (strain, New Caledonia); D. parabipectinata (17 isofemale lines, Mauritius); D. pseudoananassae (Thailand, the nigrens strain from the Bowling Green Stock Center); D. ercepeae-like (strain, Madagascar); D. ercepeae (strain, Réunion 
Table 1 Strains of $D$. ananassae used in this study. For each isofemale line, at least three individuals were tested.

\begin{tabular}{|c|c|c|c|c|c|}
\hline Name & $\begin{array}{l}\text { Geographical } \\
\text { origin }\end{array}$ & Symbol & $\begin{array}{l}\text { Type of } \\
\text { culture }\end{array}$ & $\begin{array}{l}\text { Date of } \\
\text { collection }\end{array}$ & $\begin{array}{l}\text { Number of } \\
\text { individuals }\end{array}$ \\
\hline $14024-0371-4$ & Samoa & $\mathrm{Sa}$ & Lab. strain* & 1965 & 24 \\
\hline $14024-0371-8$ & Palmyra & Py & Lab. strain* & 1962 & 9 \\
\hline $14024-0371-13$ & Tonga & $\mathrm{Tg}$ & Lab. strain* & 1962 & 9 \\
\hline $14024-0371-3$ & Hawaii & $\mathrm{Hw}$ & Lab. strain* & 1962 & 7 \\
\hline $14024-0371-15$ & Palau & $\mathrm{P}$ & Lab. strain* & 1965 & 7 \\
\hline Takapoto & Tuamotu & $\mathrm{Tk}$ & 16 isofemale lines & 1986 & 253 \\
\hline Moorea & Societe Is. & $\mathrm{M}$ & 8 isofemale lines & 1986 & 46 \\
\hline Mexico & Mexico & $\mathrm{Mx}$ & 2 isofemale lines & 1987 & 45 \\
\hline São Paulo & Brazil & SP & 1 isofemale line & 1987 & 9 \\
\hline \multirow[t]{2}{*}{ Guadeloupe } & West Indies & $\mathrm{G}$ & Mass culture & 1986 & 22 \\
\hline & & & 5 isofemale lines & 1985 & 22 \\
\hline Bouaké & Ivory Coast & B & 3 isofemale lines & 1987 & 16 \\
\hline Taï & Ivory Coast & $\mathrm{T}$ & Mass culture & 1983 & 74 \\
\hline Cotonou & Benin & $\mathrm{C}$ & 3 isofemale lines & 1987 & 33 \\
\hline \multirow[t]{2}{*}{ Djeffa } & Benin & $\mathrm{Dj}$ & 8 isofemale lines & 1987 & 134 \\
\hline & & & Wild flies & 1987 & 134 \\
\hline Brazzaville & Congo & $\mathrm{Bz}$ & Mass culture & 1987 & 17 \\
\hline Maroantsetra & Madagascar & Mt & 19 isofemale lines & 1987 & 106 \\
\hline Andasibe & Madagascar & A & 3 isofemale lines & 1987 & 24 \\
\hline Réunion & Réunion Is. & $\mathrm{R}$ & Mass culture & 1987 & 15 \\
\hline Varanasi & India & $\mathrm{V}$ & 7 isofemale lines & 1987 & 44 \\
\hline Noumea & New Caledonia & $\mathrm{N}$ & Mass culture & 1987 & 24 \\
\hline
\end{tabular}

* Bowling Green Drosophila Stock Center

Island); D. vallismaia (strain, Praslin, Seychelles); D. monieri (mass culture, Moorea); D. varians (Philippines, strain from the Bowling Green Stock Center).

Flies were reared on cornmeal standard medium and fed as adults with killed yeast medium for at least $24 \mathrm{~h}$ prior to electrophoresis. This medium does not contain sugars, which, in $D$. melanogaster, repress amylase synthesis (Benkel and Hickey, 1986). Single flies were homogeneized in $15 \mu \mathrm{l}$ distilled water, then $30 \mu \mathrm{l}$ of a 40 per cent saccharose solution was added. Samples were electrophorized on a 5 per cent polyacrylamid gel in a buffer made of Tris $0.1 \mathrm{M}$, borate $0.05 \mathrm{M}, p \mathrm{H} 8.9$. After running, gels were incubated for $1 \frac{1}{2}$ hours in a 1 per cent starch solution containing $\mathrm{CaCl}_{2} 25 \mathrm{mM}$, Tris $25 \mathrm{mM}, p \mathrm{H} 7 \cdot 5$, then stained using Lugol.

\section{RESULTS}

\section{Polymorphism in Drosophila ananassae}

Eleven different isoamylases were identified in $D$. ananassae adults. They are named either by convenient single numbers (as in D. melanogaster) or with respect to their relative mobilities: the isoamylase " 3 " corresponds to a mobility of 100 (figs 1 and 2).
The Afrotropical region shows much higher polymorphism than elsewhere, in addition few isoamylases are found in the Australasian region (fig. 3). The two isoamylases, Amy 3 and 4 are present throughout the Tropical region. Two other isoamylases, Amy 2 and $A m y 2^{\prime}$ are very close to each other and are not easy to separate, particularly in heterozygotes. The frequencies of Amy 2 and Amy 2' were pooled when both were present. Two isoamylases are common in various countries: Amy 1 and Amy 2' (table 2). Populations from Africa and Madagascar show a large variety of phenotypes while the Polynesian flies have only three, corresponding to the 2 isoamylases present. Single-banded phenotypes are very abundant in the Pacific islands and very rare in Africa, where unusual complex patterns with more than two bands (up to 5) are predominant. Since no amy-null mutant has been found in D. ananassae, we have not been able to study haplotypic structure. The frequencies of the different isoamylases are given in table 3. Amy 3 and 4 are the most common; they are almost fixed, but in some populations Amy 4 is absent (Palmyra, Tonga, Palau) and in others some individuals lack the Amy 3 band. For example, a strain homozygous for isoamylase 4 has been derived from the Takapoto population. $A m y-1$ is rare in the wild but a high frequency strain has been selected from the Taî population. 

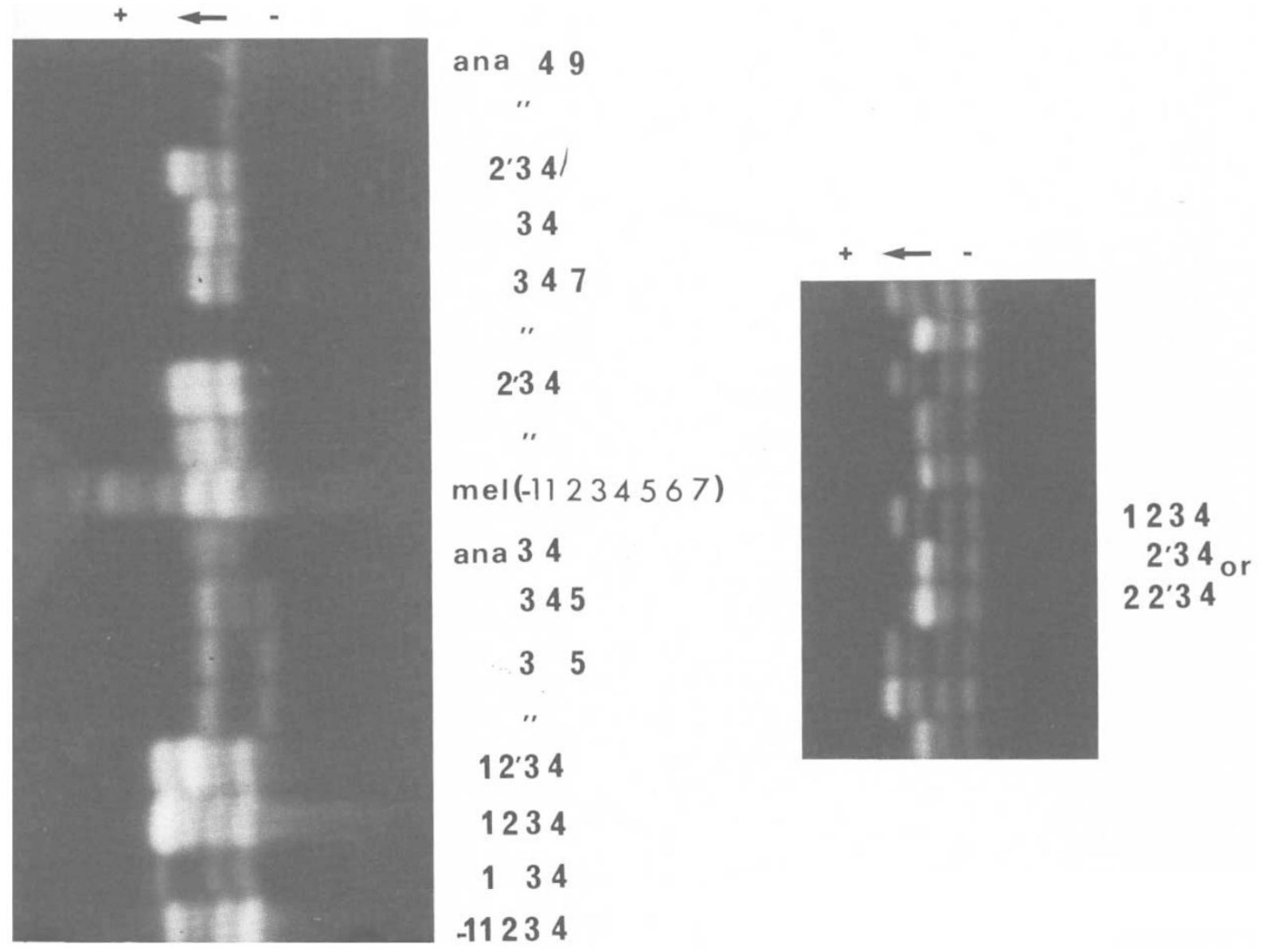

Figure 1 Various phenotypes of $D$. ananassae individuals, showing most of the isoamylases identified in the species. Complex phenotypes with five bands are clearly visible. Amylase variants of $D$. ananassae may be compared on this gel to the position of the $D$. melanogaster isoamylases.

Table 2 Percentages of different phenotypes in a few African and Pacific populations.

$A m y 9$ has not been considered here (Polynesian populations). Amy $2^{*}$ means that $A m y 2$ and/or $A m y 2^{\prime}$ are present (Djeffa population)

\begin{tabular}{|c|c|c|c|c|c|}
\hline Strain & $\begin{array}{l}\text { Djeffa } \\
\text { mass }\end{array}$ & $\begin{array}{l}\text { Djeffa } \\
\text { isofemale }\end{array}$ & Maroantsetra & Moorea & Takapoto \\
\hline \multicolumn{6}{|l|}{ Phenotype } \\
\hline Amy 3 & 0.5 & 0 & 6 & 87 & $56 \cdot 5$ \\
\hline Amy 4 & 0 & 0 & 1 & 0 & $3 \cdot 5$ \\
\hline Amy 3, 4 & $30 \cdot 5$ & 30 & 56 & 13 & 40 \\
\hline$A m y 2 *, 3$ & 1 & 0 & - & 0 & 0 \\
\hline Amy 2, 3 & - & - & 3 & 0 & 0 \\
\hline Amy 2*, 4 & 1 & 3 & 0 & 0 & 0 \\
\hline Amy $2^{*}, 3,4$ & 55 & 45 & - & 0 & 0 \\
\hline Amy $2^{\prime}, 3,4$ & - & - & 27 & 0 & 0 \\
\hline Amy $1,3,4$ & 4 & 8 & 0 & 0 & 0 \\
\hline Amy $1,2^{*}, 3,4$ & 4 & 1 & 0 & 0 & 0 \\
\hline Amy $3,4,5$ & 0 & 0 & $4-5$ & 0 & 0 \\
\hline Amy $2^{\prime}, 3,4,5$ & 0 & 0 & 2 & 0 & 0 \\
\hline Amy $3,4,7$ & 1 & 4 & 0 & 0 & 0 \\
\hline $\operatorname{Amy} 2^{*}, 3,4,7$ & 0.5 & 7 & 0 & 0 & 0 \\
\hline
\end{tabular}




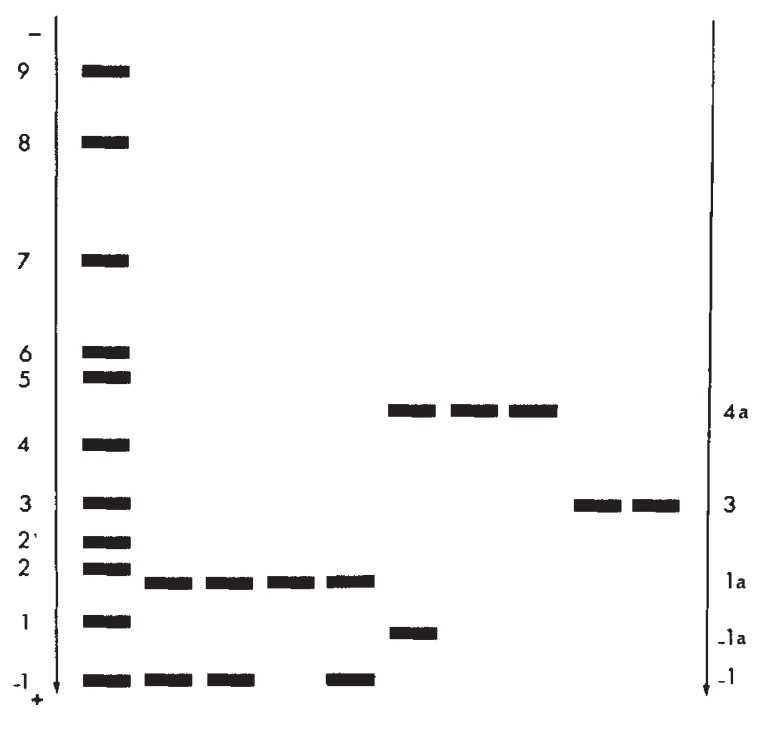

ana mal pse bip par elk erc val mon var

Figure 2 Relative positions of the different isoamylases found in $D$. ananassae (ana); $D$. malerkotliana (mal); $D$. pseudoananassae (pse); D. bipectinata (bip); D. parabipectinata (par); D. ercepeae-like (elk); D. ercepeae (erc); $D$. vallismaia (val); D. monieri (mon); D. varians (var). Position 100 was given to the most common allele of $D$. ananassae (Amy 3).
Amy 1 and $2^{\prime}$ are common in Africa, the Indian Ocean and Tropical America, with a high frequency for Amy $2^{\prime}$ in the Equatorial populations of Africa. Amy 2 is reported from Equatorial Africa. The other isoamylases are geographically limited: Amy 5 to Madagascar and Guadeloupe, Amy 6 (observed only once) and 7 to Benin and Amy 9 to French Polynesia. A very slow band similar to Amy 9 has been reported in species of the $D$. melanogaster subgroup ( $D$. melanogaster, $D$. simulans, D. teissieri) where it has not been ascribed with certainty to the usual gene-enzyme system (Cariou, unpublished data). Amy 8 appears in a few individuals from Africa.

The amylase pattern in other species of the D. ananassae subgroup

Fig. 2 shows that for all the species studied here, single banded phenotypes are predominant. $D$. malerkotliana, D. bipectinata, D. parabipectinata, and $D$. pseudoananassae have a common band, slightly faster than the Amy 2 of $D$. ananassae. That band may correspond to the same allele for these four species. In addition, two isofemale lines of D. malerkotliana (one from Madagascar and one from Ecuador), and some individuals of $D$.

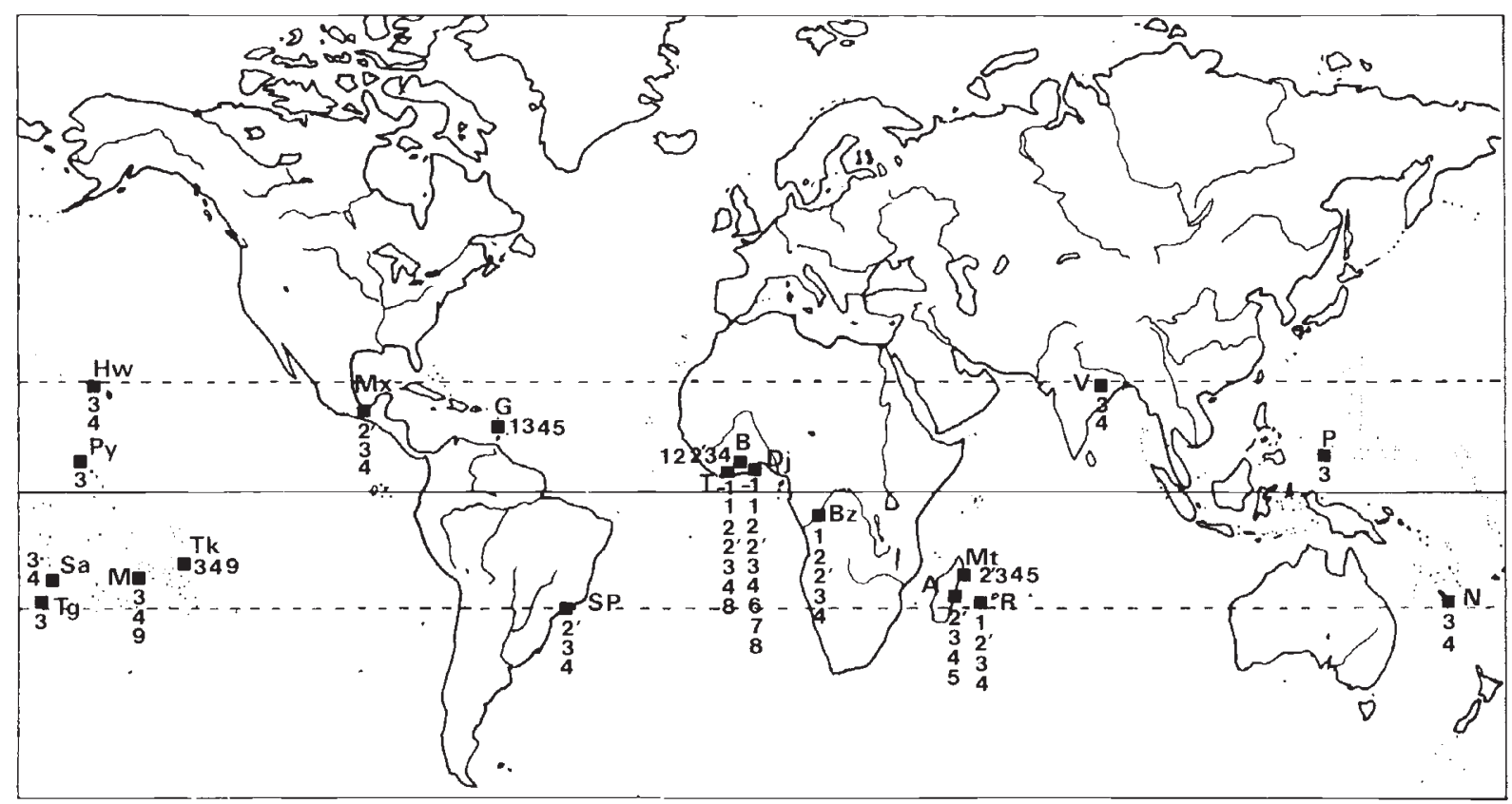

Figure 3 Geographical distribution of amylase isozymes in D. ananassae. Symbols of localities are given in table 1. 
Table 3 Percentages of individuals carrying each isoamylase in the different localities

\begin{tabular}{|c|c|c|c|c|c|c|c|c|c|c|c|}
\hline \multicolumn{12}{|l|}{ Isoamylases } \\
\hline & -1 & 1 & 2 & $2^{\prime}$ & 3 & 4 & 5 & 6 & 7 & 8 & 9 \\
\hline \multicolumn{12}{|l|}{ Strains } \\
\hline Samoa & 0 & 0 & 0 & 0 & 100 & 80 & 0 & 0 & 0 & 0 & 0 \\
\hline Palmyra & 0 & 0 & 0 & 0 & 100 & 0 & 0 & 0 & 0 & 0 & 0 \\
\hline Hawaii & 0 & 0 & 0 & 0 & 100 & 100 & 0 & 0 & 0 & 0 & 0 \\
\hline Takapoto & 0 & 0 & 0 & 0 & $96 \cdot 5$ & $43 \cdot 5$ & 0 & 0 & 0 & 0 & see text \\
\hline Moorea & 0 & 0 & 0 & 0 & 100 & 20 & 0 & 0 & 0 & 0 & see text \\
\hline Mexico & 0 & 0 & 0 & 29 & 100 & 96 & 0 & 0 & 0 & 0 & 0 \\
\hline São Paulo & 0 & 0 & 0 & 22 & 100 & 100 & 0 & 0 & 0 & 0 & 0 \\
\hline Guadeloupe & 0 & 11 & 0 & 0 & 100 & 1001 & 8 & 0 & 0 & 0 & 0 \\
\hline Bouaké & 0 & 25 & \multicolumn{2}{|c|}{28} & 100 & 100 & 0 & 0 & 0 & 0 & 0 \\
\hline Brazzaville & 0 & 8 & \multicolumn{2}{|c|}{80} & 100 & 100 & 0 & 0 & 0 & 0 & 0 \\
\hline Maroantsetra & 0 & 0 & 0 & 32 & 99 & 91 & 6.5 & 0 & 0 & 0 & 0 \\
\hline Andasibe & 0 & 0 & 0 & 8 & 100 & 96 & 8 & 0 & 0 & 0 & 0 \\
\hline Réunion & 0 & 33 & 0 & 33 & 100 & 100 & 0 & 0 & 0 & 0 & 0 \\
\hline Varanasi & 0 & 0 & 0 & 0 & 100 & 100 & 0 & 0 & 0 & 0 & 0 \\
\hline Noumea & 0 & 0 & 0 & 0 & 86 & 100 & 0 & 0 & 0 & 0 & 0 \\
\hline
\end{tabular}

parabipectinata and $D$. pseudoananassae show a second, common band, faster than the former. $D$. ercepeae, $D$. vallismaia and $D$. ercepeae-like share a band which is slightly slower than Amy 4 of $D$. ananassae. $D$. ercepeae-like shows a second, faster isoamylase. Finally, D. monieri and $D$. varians express a single amylase band that has the same mobility as the $D$. ananassae isoamylase 3 .

\section{DISCUSSION}

Many $D$. ananassae individuals, especially in Africa, show complex phenotypes with three, four and sometimes five bands. Because of the monomeric structure of the amylase protein, any electrophoretic pattern with more than two bands may indicate a multiplication of the coding gene. The duplication of the Amy locus is well established in the D. melanogaster subgroup (Boer and Hickey, 1986; Doane et al, 1987 Daïnou et al, 1987; Payant et al, 1988). In $D$. ananassae the exact number of gene copies remains questionable but more than two active copies must exist in at least some individuals or populations: the five-banded individuals strongly suggest a triplication of the Amy gene. A stable strain, homogeneous for Amy 2.3.4. and therefore considered to be homozygous for these three alleles, has also been derived from the Taï population. In addition, some crosses (data not shown) between an Amy 1.2.3.4 male from Taï (where $A m y 4$ is fixed) and an $A m y$ 4 female from Takapoto produce some Amy 1.2.3.4 F1 individuals, indicating that not only $A m y 1.2$ and 3, but also $A m y$ 4, are transmitted paternally. Another cross with an $A m y 3$ female instead of $A m y 4$ leads to the same conclusion that four copies of the $A m y$ gene may be present in the paternal haploid genome. We are not able yet to show whether each population of $D$. ananassae harbours the same number of copies. Some populations exhibit a single isoamylase, but a singlebanding pattern is not evidence for a single locus (Doane et al, 1987).

D. ananassae also shows a marked geographic differentiation for amylase polymorphism: populations from Africa and the Indian Ocean are much more polymorphic and have the greatest allelic diversity. A similar geographic pattern has been reported in D. melanogaster. For this species, Daïnou et al., (1987) explained the high number of alleles in Africa using historical arguments, since D. melanogaster is thought to have originated in West Africa. In the case of $D$. ananassae, the ancestral populations probably lived in the Far East (Dobzhansky and Dreyfus, 1943). Populations from that region might then be expected to have high polymorphism. Our results do not support this, and the scarcity of alleles in South East Asia is difficult to explain. We lack data from 
Indonesia, New Guinea and Australia and in some cases, we assayed very old laboratory strains probably founded by few individuals that might not be representative of natural populations.

$D$. ananassae and D. melanogaster are both domestic species which have spread from Africa to America through man's activities. Interestingly, African and American populations of $D$. ananassae share several alleles. The high polymorphism in Africa might suggest an ancient colonization of this region, but if the number of Amy gene copies is variable within the species, the difference of levels of polymorphism between Africa and Asia might also be explained by a higher number of functional loci in African populations.

The other species of the $D$. ananassae subgroup, which have weaker activity, show low polymorphism. Within the D. ananassae subgroup, our results are consistent with the taxonomy: $D$. bipectinata, D. parabipectinata, D. malerkotliana, and D. pseudoananassae, which constitute the bipectinata complex, and produce, in interspecific crosses, fertile $F_{1}$ females (Lemeunier et al., 1986), show the same major isoamylase. D. malerkotliana, $D$. parabipectinata and $D$. pseudoananassae frequently share an additional band. D. ercepeae, $D$. ercepeae-like and $D$. vallismaia belong to the ercepeae complex and are more distantly related to $D$. ananassae. These three species show a common isoamylase. D. monieri and $D$. varians belong to the ananassae complex. Both have a single isoamylase similar to Amy 3 of D. ananassae. This result could suggest that $A m y$, the most widespread allele in $D$. ananassae, might be ancestral.

\section{REFERENCES}

ABE, K. 1958 Genetical and biochemical studies in amylase in Drosophila melanogaster. Jap. J. Genet., 33, 138-145.

BAHN, E. 1967. Crossing over in the chromosomal region determining amylase isozymes in Drosophila melanogaster. Hereditas, 58, 1- 12 .

BENKEL, B. F. AND HICKEY, D. A. 1986. Glucose repression of amylase gene expression in Drosophila melanogaster. Genetics, 114, 137-144.

BOER, P. H. AND HICKEY, D. A. 1986 . The alpha-amylase gene in Drosophila melanogaster: nucleotide sequence, gene structure and expression motifs. Nucleic Acids Res., 14, $8399-8411$
DAÏNOU, O. 1985. Polymorphisme et rôle physiologique de l'amylase chez Drosophila melanogaster et espèces affines. Thèse de 3ème cycle, Univ. Paris 7, $178 \mathrm{pp}$.

DAÏNOU, O., CARIOU, M.-L., DAVID, J. R., AND HICKEY, D. 1987. Amylase gene duplication: an ancestral trait in the Drosophila melanogaster species subgroup. Heredity, 59, 245-251.

DAVID, J. R. AND TSACAS, L. 1981. Cosmopolitan, subcosmopolitan and widespread species: different strategies in the Drosophilid family (Diptera). C.R. Soc. Biogeog., 57, 11-26.

DOANE, W. W. 1965. Genetic control of amylase activity in Drosophila melanogaster. Proc. XII Int. Congr. Ent., London 1964, 233-234.

DOANE, W. W. AND NORMAN, R. A. 1985. Amylase gene family in sibling Drosophila species - miranda, persimilis, pseudoobscura: Polytene chromosome sites with Amy sequence homologies. Genetics, 110, S37.

DOANE, W. W., GEMMILL, R. M., SCHWARTZ, P. E., HAWLEY, S. A., NORMAN, R. A. 1987. Structural organization of the Alpha-amylase Gene Locus in Drosophila melanogaster and Drosophila miranda. Isozymes: Current Topics in Biological and Medical Research, 14, 229-266.

DOBZHANSKY, T. AND DREYFUS, A. 1943. Chromosomal aberrations in Drosophila ananassae. Proc. Natl Acad. Sci. USA, 29, 301-305.

GEMMILL, R. M., LIVVY, J. N. AND DOANE, W. W. 1985. Molecular cloning of alpha-amylase genes from Drosophila melanogaster. I: Clone isolation by use of a mouse probe. Genetics, 110, 299-312.

HICKEY, D. A. 1979. The geographical pattern of an enzyme polymorphism in D. melanogaster, Genetica, 51, 1-4.

KIKKAWA, H. 1960. Further studies on the genetic control of amylase in Drosophila melanogaster. Jap. J. Genet., 35, 382-387.

KIKKAWA, H. 1964. An electrophoretic study on amylase in Drosophila melanogaster. Jap. J. Genet., 39, 401-411.

LEMEUNIER, F., TSACAS, L., DAVID, J., AND ASHBURNER, M. 1986. The melanogaster species group. In Ashburner, M., Thompson, J. R. Jr. and Carson, H. L. (eds.) The Genetics and Biology of Drosophila, Vol. 3, Academic Press, London and New York, pp. 147-256.

MCEVEY, S. F., DAVID, I. R, AND TSACAS, L. 1987. The Drosophila ananassae complex with descriptionn of a new species from French Polynesia (Diptera: Drosophilidae). Annls. Soc. ent. Fr. (N.S.) 23, 377-385.

PAYANT, V., ABUKASHAWA, S., SASSEVILLE, M., BENKEL, B., HICKEY, D., AND DAVID, J. 1988. Evolutionary conservation of the chromosomal configuration and regulation of Amylase genes among eight species of the Drosophila melanogaster species subgroup. Mol. Biol. Evol., 5, 560-567.

SINGH, B. N., 1985. Drosophila ananassae-a genetically unique species. The Nucleus, 28, 169-176.

TSACAS, L. 1984. Nouvelles données sur la biogéographie et l'évolution du groupe Drosophila melanogaster en Afrique. Description de six nouvelles espèces. (Diptera, Drosophilidae). Annls. Soc. ent. Fr. (N.S.), 20, 419-438. 